\title{
Hemolytic and urease activities in vibrios isolated from fresh and frozen oysters
}

\author{
Renata Albuquerque Costa ${ }^{[1],[2], ~ R a y z a ~ L i m a ~ A r a u ́ j o ~}{ }^{[1]}$ and \\ Regine Helena Silva dos Fernandes Vieira ${ }^{[1],[2]}$
}

[1]. Departamento de Engenharia de Pesca, Universidade Federal do Ceará, Fortaleza, CE. [2]. Laboratório de Microbiologia Ambiental e do Pescado, Instituto de Ciências do Mar, Universidade Federal do Ceará, Fortaleza, CE.

\begin{abstract}
Introduction: The present study aimed to survey the Vibrio microbiota of oysters (Crassostrea rhizophorae) obtained from restaurants in Fortaleza, State of Ceará, Brazil, and to identify virulence factors. Methods: The isolated vibrios were submitted to biochemical identification and were tested for hemolytic and urease activities. Results: The isolated strains belonged to 13 species, with predominance of Vibrio mimicus. Of the strain isolates only from fresh samples, $20.5 \%$ and $2.8 \%$ showed hemolytic and urease activities, respectively. Conclusions: The findings support the little-publicized claim that Vibrio species other than $V$. parahaemolyticus and $V$. vulnificus can represent a health risk to public health.
\end{abstract}

Keywords: Vibrio. Crassostrea rhizophorae. Virulence factors.

Vibrios are part of the native microbiota of marine environments and organisms. Up to $40 \%$ of water-column bacteria are associated with zooplankton. Among these, vibrios have a competitive advantage in the colonization of chitinous exoskeletons ${ }^{1}$. Due to their abundance in the water column, vibrios may be up to a hundred times more concentrated in filter-feeding mollusks than in the immediate environment ${ }^{2}$.

Since vibrios are part of the autochthonous bacterial community colonizing bivalves, it comes as no surprise that they have been implicated in many outbreaks related to oyster consumption. The vibrio species most often associated with disease from consumption of oysters in natura are Vibrio parahaemolyticus, V. vulnificus, and V. cholerae ${ }^{3}$. However, virulence factors similar to those displayed by $V$. parahaemolyticus are detected in other vibrio species with increasing frequency. Thus, Nishibuchi et $a .^{4}$ found that $V$. hollisae strains from clinical samples can carry the hemolysinencoding gene $t d h$, a marker of virulence. Other vibrio species isolated from marine organisms have also been shown to be capable of $\beta$-hemolysis 5 .

The objective of the present study was to survey the Vibrio microbiota of fresh and frozen oysters (Crassostrea rhizophorae) obtained from restaurants in Fortaleza, and to identify phenotypical virulence factors by testing strains for $\beta$-hemolysis and urease activity.

The study was based on 15 samples of fresh oysters and 15 samples of frozen oysters (C. rhizophorae) obtained from two restaurants in Fortaleza City (Northeastern Brazil) between August 2009 and August 2010. Each sample consisted of 10

Address to: Dra. Renata Albuquerque Costa. LABOMAR/Instituto de Ciências do Mar/UFC. Av. Abolição 3207, 60165-081 Fortaleza, CE, Brasil.

Phone: 5585 3366-7027

e-mail: renata.albuq@gmail.com

Received in 17/04/2011

Accepted in 30/09/2011 specimens, for a total of 300 specimens examined. Oysters with closed valves were placed in labeled polyethylene bags and transported in isothermal boxes to the Laboratory of Seafood and Environmental Microbiology (LABOMAR/UFC) for processing. Transportation did not exceed two hours.

The oysters were washed in tap water and vigorously scrubbed, then opened under aseptic conditions for retrieval of the intervalvular tissues and fluid. A 50-gram portion was taken from each sample of 10 specimens and added to $450 \mathrm{~mL}$ alkaline peptone water $(\mathrm{pH} 8.5)$ containing $1 \% \mathrm{NaCl}$. The sample was homogenized in a magnetic stirrer (Cole Parmer, Model 51450) for 15min. The homogenate (which corresponded to a $10^{-1}$ dilution) was used to make serial decimal dilutions from $10^{-2}$ to $10^{-4}$.

Subsequently, $0.2 \mathrm{~mL}$ aliquots of each dilution were spreadplated on thiosulfate-citrate-bile salt-sucrose agar (TCBS-Difco) and incubated at $35^{\circ} \mathrm{C}$ for $18 \mathrm{~h}$. Three yellow or blue-green colonies for each sample were randomly select and cultured in tryptone soy agar (TSA-Difco) supplemented with $1 \% \mathrm{NaCl}$. All colonies were submitted to biochemical identification using the key developed by Noguerola and Blanch ${ }^{6}$. The following metabolic parameters were measured: lysine and ornithine decarboxylation; arginine hydrolysis; indole and $\mathrm{H}_{2} \mathrm{~S}$ production; gelatinase; oxidase; sucrose consumption; mannitol; melibiose; arabinose and D-glucosamine; growth at $4^{\circ} \mathrm{C}, 35^{\circ} \mathrm{C}$, and $40^{\circ} \mathrm{C}$; growth at $0,6,8$, and $10 \% \mathrm{NaCl}$; ONGP (o-nitrophenyl- $\beta$-D-galactopyranoside); resistance to $10 \mu \mathrm{g}$ ampicillin and $10 \mu \mathrm{g} \mathrm{O} / 129$; Voges-Proskauer test (acetoin); citrate; and nitrate reduction. Urease activity was tested in the medium Stuart, van Stratum \& Rustigian. All the media used for identification contained $1 \% \mathrm{NaCl}$.

The isolates were grown on Wagatsuma agar supplemented with $20 \%$ defibrinated sheep blood (modification), incubated at $35^{\circ} \mathrm{C}$ for $24 \mathrm{~h}$. A positive control strain (Kanagawa-positive V. parahaemolyticus IOC 18950) was used. 
Eleven Vibrio species were identified in the microbiota of fresh samples, compared with five species in frozen samples (Table 1). Only three species (V. rumoiensis, V. coralliilyticus, and $V$. litoralis) were isolated from fresh and frozen oysters concomitantly. The species $V$. mimicus, $V$. ponticus, $V$. hepatarius, V. proteolyticus, V. lentus, V. natriegens, $V$. pelagius I, and $V$. scophthalmi were isolated from fresh samples only. On the other hand, $V$. vulnificus and $V$. diazotrophicus were detected only in the microbiota of frozen samples.

Seven strains (20.5\% of total) belonging to five species tested were hemolytic-positive in Wagatsuma agar. Only one (2.8\%) of our 35 Vibrio strains was capable of ureolysis (Table 2). None of our strains were both Kanagawa-positive and ureolytic.

TABLE 1 - Vibrios isolated from 15 fresh and 15 frozen samples of oyster obtained from restaurants in Fortaleza, State of Ceará, Brazil.

\begin{tabular}{lccc} 
& & \multicolumn{2}{c}{ Origin of strains } \\
\cline { 3 - 4 } Isolated Vibrio species & Strains (n) & Fresh oyster & Frozen oyster \\
\hline Vibrio mimicus & 5 & 5 & - \\
Vibrio hepatarius & 4 & 4 & - \\
Vibrio ponticus & 4 & 4 & - \\
Vibrio proteolyticus & 4 & 4 & - \\
Vibrio vulnificus B3 & 4 & - & 4 \\
Vibrio rumoiensis & 3 & 1 & 2 \\
Vibrio coralliilyticus & 2 & 1 & 1 \\
Vibrio diazotrophicus & 2 & - & 2 \\
Vibrio litoralis & 2 & 1 & 1 \\
Vibrio lentus & 1 & 1 & - \\
Vibrio natriegens & 1 & 1 & - \\
Vibrio pelagius I & 1 & 1 & - \\
Vibrio scophthalmi & 1 & 1 & - \\
\hline
\end{tabular}

TABLE 2 - Vibrio species isolated from fresh oyster, with phenotypical profiles compatible with urease and hemolytic activities

\begin{tabular}{lcc}
\hline Test & Strains (n) & Species (n of strains) \\
\hline & & Vibrio proteolyticus (3) \\
$\beta$-hemolysis & 7 & Vibrio pelagius I (1) \\
& & Vibrio ponticus (1) \\
& & Vibrio rumoiensis (1) \\
Urease & 1 & Vibrio coralliilyticus (1) \\
\hline
\end{tabular}

The Vibrio diversity was greater in fresh than in frozen samples, suggesting that handling and storage practices have an impact on bacterial diversity and confirming the claim that vibrio proliferation is greater at room temperature than under cold storage. This is supported by Pereira et al. ${ }^{7}$, according to whom prolonged storage of oysters at room temperature favors bacterial multiplication.
The most frequently isolated species were $V$. mimicus (fresh samples) and V. vulnificus B3 (frozen samples). The former has been reported abundantly in the literature since the early 1980s. Thus, Shandera et al. ${ }^{8}$ described the clinical and epidemiological characteristics of infection caused by $V$. mimicus and concluded that the species should be considered in the differential diagnosis of acute gastroenteritis following ingestion of seafood, especially oysters in natura.

The detection of $V$. vulnificus in frozen oyster samples does not match the findings of Prapaiwong et al. ${ }^{9}$, who observed the species in fresh samples only. However, Bryan et al. ${ }^{10}$ suggested that the effectiveness of rapid freezing of oysters to reduce $V$. vulnificus levels may be compromised by product handling procedures that permit cold adaptation. The authors emphasize than this adaptive nature to cold temperatures could be important for shellfish industry efforts to reduce the risk of $V$. vulnificus infection from consuming raw oysters.

The index of isolation of $V$. vulnificus in our study (11.4\%) is disquieting and high enough to make positive samples a potential source of infection. According to Daniels ${ }^{11}$, oysters are the most common vehicle of transmission of $V$. vulnificus infection, which manifests in the form of gastroenteritis, primary septicemia, or wound infection, accompanied by fever, chills, diarrhea, nausea, vomiting, septic shock, and characteristic skin lesions.

Seven $(53.8 \%)$ of the 13 vibrio species identified in this study were recently described for the first time: V. scophthalmi, $V$. rumoiensis, V. lentus, $V$. hepatarius, $V$. coralliilyticus, $V$. ponticus, and $V$. litoralis. The type strains used to characterize the vibrio species above were isolated from aquatic organisms sampled in coastal areas, marine environments, and/or the fishing industry. Of particular interest is $V$. lentus, which was first characterized based on 12 strains isolated from Mediterranean oysters $^{12}$.

In view of the importance of determining the level of virulence in vibrio strains isolated from oysters destined for human consumption, all strains $(\mathrm{n}=35)$ were tested for their ability to hydrolyze urea and produce hemolysin - two wellestablished indicators of pathogenicity in vibrios. In the present study only fresh oyster samples showed hemolytic activity in Wagatsuma agar and strong positive urease production (Table 2).

Detected phenotypically by the observation of $\beta$-hemolysis, the phenomenon Kanagawa is triggered by the expression of the gene $t d h$, which encodes thermostable direct hemolysin (TDH), a determining factor of virulence in V. parahaemolyticus strains. However, functional TDH production depends on two genes, $t d h 1$ and $t d h 2$, of which only the latter is capable of hemolytic activity ${ }^{13}$.

Although most studies on Kanagawa positivity focus on the species $V$. parahaemolyticus, other vibrio species may occasionally carry $t d h$ highly homologous to the genes known from $V$. parahaemolyticus ${ }^{4}$. This was borne out in our study by the finding of $\beta$-hemolysis in species other than V. parahaemolyticus. 
The species $V$. proteolyticus, V. pelagius I, V. ponticus, $V$. rumoiensis, and V. coralliilyticus showed hemolytic activity (Table 2). Likewise, strains of $V$. coralliilyticus isolated from scallops (Nodipecten nodosus) and coral (Pocillopora damicornis) were shown by Austin et al. ${ }^{5}$ to produce hemolysin in sheep blood.

Isolation of urease-positive $V$. litoralis (Table 2) may be indicative of health risk to consumers of fresh oyster. According to Mobley ${ }^{14}$, ureolysis is observed in a wide range of taxonomically different bacteria, the pathogenicity of which appears to be related to their ability to colonize the gastric mucosa and protect themselves from the acid environment of the stomach. In vibrios, especially $V$. parahaemolyticus, the phenotypical detection of urease may be considered a marker of virulence for TDH-related hemolysin (TRH) production and, consequently, indicates the presence of the gene $t r h^{15}$.

The virulence factors were not expressed simultaneously in any strain. Similarly, Pereira et al..$^{7}$ only observed ureolysis in Kanagawa-negative strains of $V$. parahaemolyticus.

The findings of this study support the little-publicized claim that vibrio species other than $V$. parahaemolyticus and $V$. vulnificus can represent a health risk to consumers of oysters. In addition, frozen storage was shown to reduce vibrio diversity and, consequently, the risk of bacterial infection associated with the consumption of fresh oysters.

\section{CONFLICT OF INTEREST}

The authors declare that there is no conflict of interest.

\section{REFERENCES}

1. Heidelberg J, Heidelberg KB, Colwell RR. Bacteria of the gamma-subclass Proteobacteria associated with zooplankton in Chesapeake Bay. Appl Environ Microbiol 2002; 68:5498-5507.
2. Wright AC, Hill RT, Johnson JA, Roghman M-C, Colwell RR, Morris Jr JG. Distribution of Vibrio vulnificus in the Chesapeake Bay. Appl Environ Microbiol 1996; 62:717-724.

3. Panicker G, Call DR, Krug MJ, Bej AK. Detection of pathogenic Vibrio spp. in shellfish by using multiplex PCR and DNA microarrays. Appl Environ Microbiol 2004; 70:7436-7444.

4. Nishibuchi M, Janda JM, Ezaki T. The thermostable direct hemolysin gene $(t d h)$ of Vibrio hollisae is dissimilar in prevalence to and phylogenetically distant from the $t d h$ genes of other vibrios: implications in the horizontal transfer of the $t d h$ gene. Microbiol Immunol 1996; 40:59-65.

5. Austin B, Austin D, Sutherland R, Thompson F, Swings J. Pathogenicity of vibrios to rainbow trout (Oncorhynchus mykiss, Walbaum) and Artemia nauplii. Environ Microbiol 2005; 7:1488-1495.

6. Noguerola I, Blanch AR. Identification of Vibrio spp. with a set of dichotomous keys. J Appl Microbiol 2008; 105:175-185.

7. Pereira CS, Viana CM, Rodrigues DP. Vibrio parahaemolyticus produtores de urease isolados a partir de ostras (Crassostrea rhizophorae) coletadas in natura em restaurante e mexilhões (Perna perna) de banco natural. Ciênc. Tecnol Aliment 2004; 24:591-595.

8. Shandera WX, Johnston JM, Davis BR, Blake PA. Disease from infection with Vibrio mimicus, a newly recognized Vibrio species clinical characteristics and epidemiology. Ann Intern Med 1983; 99:169-171.

9. Prapaiwong N, Wallace RK, Arias CR. Bacterial loads and microbial composition in high pressure treated oyster during storage. Int J Food Microbiol 2009; 131:145-150

10. Bryan PJ, Steffan RJ, DePaola A, Foster JW, Bej AK. Adaptive response to cold temperatures in Vibrio vulnificus. Curr Microbiol 1999; 38:168-175.

11. Daniels NA. Vibrio vulnificus oysters: pearls and perils. Clin Infect Dis 2011; 52:788-792.

12. Macián MC, Ludwig W, Aznar R, Grimont PAD, Schleifer KH, Garay E, et al. Vibrio lentus sp. nov., isolated from Mediterranean oysters. Int J Syst Evol Microbiol 2001; 51:1449-1456.

13. Nishibushi M, Kaper JB. Thermostable direct hemolysin gene of Vibrio parahaemolytcius: a virulence gene acquired by a marine bacterium. Infect Immun 1995; 63:2093-2099.

14. Mobley HLT. Urease. In: Mobley HLT, Mendz GL, Hazell SL, editors. Helicobacter pylori: Physiology and Genetics. Washington DC: ASM Press; 2001. p. 179-192.

15. Ghosh AR, Sehgal SC. Detection of $t d h$ and $t r h$ genes in a urea-hydrolysing environmental isolate of Vibrio parahaemolytcius from Andamans. J Diarrhoeal Dis Res 1998; 16:87-90. 